\title{
A novel peptide RIFV suppresses human adipocyte differentiation through the inhibition of C/EBP- $\beta$ expression
}

\author{
Wen Zhang ${ }^{1,2 \dagger}$, Dan Shen ${ }^{1+}$, Yun $\mathrm{Li}^{1}$, Hong Zhong ${ }^{1}$, Xing Wang ${ }^{1}$, Xian-wei Cui ${ }^{1}$, Chun-Mei Shi ${ }^{1}$, Chen-Bo Ji ${ }^{1}$, \\ Xi-Rong Guo ${ }^{3^{*}}$ and Ling Chen ${ }^{1 *}$
}

\begin{abstract}
Background: Obesity is a global epidemic disease that increases the risk of metabolic syndrome. However, therapeutic drugs for obesity are still scarce. In recent years, peptides have been identified as new biological regulators. RIFV (R-I-F-V-P-I-K-G-R-P-A-P), a novel active peptide from our peptide database.
\end{abstract}

Methods: We performed oil red $O$ staining and triglyceride measurement to analyze the influence of RIFV on white preadipocytes differentiation. Then the effects of RIFV on cell proliferation, apoptosis and cell cycle were determined by using CCK-8 assay and flow cytometry. The mRNA and protein levels of adipogenesis-related genes were respectively detected by qRT-PCR and western blot. Rescue experiment was conducted to confirm whether RIFV could regulate adipocytes differentiation via targeting C/EBP- $\beta$. Finally, the luciferase reporter gene assay was performed to verify the regulation of RIFV on C/EBP- $\beta$ gene.

Results: RIFV was revealed to inhibit the differentiation of human white adipocytes without affecting their proliferation. Additionally, RIFV could also suppress the differentiation of mouse primary white preadipocytes isolated from inguinal fat tissues. Furthermore, RIFV may have an inhibitory effect on adipogenesis by inhibiting the regulation of the adipogenic gene C/EBP- $\beta$.

Conclusions: Our results indicated that RIFV may be a novel essential regulator of adipocyte differentiation and represents a therapeutic strategy for obesity and related complications.

Keywords: RIFV, Peptides, Adipocyte differentiation, C/EBP- $\beta$

\section{Introduction}

Obesity is ascribed to excessive fat accumulation, which is a major risk factor for many metabolic diseases, such as hypertension, diabetes, cardiovascular disease and certain types of cancer $[1,2]$. Obesity has been a worldwide public health problem. However, therapeutic medicine to treat obesity is still limited. Most of clinical medications play a role in weight loss mainly via inhibiting appetite, which is often associated with side effects [3, 4]. Therefore, it is very important to find new therapies to treat obesity.

\footnotetext{
* Correspondence: GXR4185@shtrhospital.com; xochenling@163.com 'Wen Zhang and Dan Shen contributed equally to this work.

${ }^{3}$ Hongqiao International Institute of Medicine, Tongren Hospital, Shanghai Jiao Tong University School of Medicine, Shanghai, China

'Department of Pediatrics, Nanjing Maternity and Child Health Care Hospital, Women's Hospital of Nanjing Medical University, Nanjing 210029, China Full list of author information is available at the end of the article
}

Previous studies have suggested that various substances, such as microRNA [5, 6], animal venom [7] and plant extracts [8], could affect the formation and metabolism of adipocytes by affecting the functions of important transcription factors. Lot of researches had focused on the therapeutic potential of these substances in the treatment of obesity. However, animal venom or plant extracts are usually a complex mixture and are more likely to have side effects $[7,8]$. In comparison, microRNA is with single component and functions mostly by targeting specific mRNA gene $[5,6]$. It's worth noting that some microRNAs based drugs have been utilized in clinical trials to treat different disease. However, there is few about obesity $[9,10]$.

In recent years, as a new biological regulator, peptides have attracted increasing attention, which have been involved in many physiological and pathological processes,

C The Author(s). 2019 Open Access This article is distributed under the terms of the Creative Commons Attribution 4.0 International License (http://creativecommons.org/licenses/by/4.0/), which permits unrestricted use, distribution, and 
such as cardiovascular disease [11], infection [12], diabetes [13] and obesity [14]. Until now, some antiobesity peptides have already been utilized as therapeutic agents in clinical application. For instance, the analog of glucagon-like peptide 1 (GLP-1), liraglutide, has shown greater weight loss by decreased food intake and delayed gastrointestinal emptying [15]. Beyond liraglutide, the US FDA has already approved a total of six GLP-1-based drugs: exenatide, lixisenatide, liraglutide, semaglutide, dulaglutide and albiglutide [16]. In the clinic, doctors can prescribe these medications to patients with obesity or type 2 diabetes by extending the duration of action on the GLP-1 receptor. Notably, GLP-1 and its analogs also have unwanted side effects, such as nausea and pancreatitis $[17,18]$.

Recently, researchers have paid attention to some alternative peptides related to obesity treatment owing to their potential for animals without causing significant adverse effects. For instance, the analog of the sea anemone-derived peptide ShK, ShK-186, has been implicated in lowering the body weight gain, lipid accumulation, and inflammatory infiltration of high fat-induced obese mice $[19,20]$. The polypeptide $\mathrm{pNaKtide,} \mathrm{which} \mathrm{is}$ from the nucleotide-binding domain of the $\alpha$ subunit of $\mathrm{Na} / \mathrm{K}$-ATPase, can attenuate lipid accumulation and oxidative stress in 3T3L1 adipocytes in a dose-dependent manner by antagonizing the $\mathrm{Na} / \mathrm{K}$-ATPase-mediated amplification of ROS signaling. In vivo, the treatment of obese mice with pNaKtide showed reduced bodyweight gain and improved insulin sensitivity [21].

In this study, we screened a novel peptide, termed RIFV (sequence R-I-F-V-P-I-K-G-R-P-A-P), which contains 12 amino acids. RIFV was identified from our peptide database, which was established from human tissues, blood and other body fluids. Through functional screening, we identified that RIFV could inhibit human adipocyte differentiation but did not influence proliferation and apoptosis of these cells. In addition, we found that the inhibition effect of RIFV on differentiation was conserved in mouse primary white preadipocytes isolated from inguinal fat tissues. Furthermore, RIFV may have an inhibitory effect on adipogenesis by inhibiting the regulation of the adipogenic gene C/EBP- $\beta$. Our results indicate that RIFV acts as a negative regulator of adipogenesis.

\section{Materials and methods}

\section{Cell culture and differentiation of human white preadipocytes}

Human white preadipocytes (hWA; purchased from ScienCell Research Laboratories) were cultured and maintained in preadipocyte medium (PAM; ScienCell Research Laboratories) containing 5\% fetal bovine serum (FBS), 1\% preadipocyte growth supplement(PAGS), and $1 \%$ penicillin/streptomycin $(\mathrm{P} / \mathrm{S})$ at $37^{\circ} \mathrm{C}$ in a humidified atmosphere under $5 \% \mathrm{CO}_{2}$. After 2 days of cell culture, the confluent cells were exposed to differentiation medium for 4 days. The induction medium contained PAM without serum, supplemented with $0.5 \mathrm{mM} \mathrm{3-}$ isobutyl-1-methylxanthine (IBMX; Sigma, St. Louis, MO, USA), $100 \mathrm{nM}$ insulin (Sigma), $1 \mu \mathrm{M}$ dexamethasone (Sigma), and $1 \mu \mathrm{M}$ rosiglitazone (Sigma). Then, the medium was changed to serum-free PAM with $10 \mathrm{nM}$ insulin every 2 days until the accumulation of lipid droplets was observed.

\section{Isolation and differentiation of mouse white preadipocytes}

Mouse primary white preadipocytes (mWA) were isolated from the stromal vascular fraction (SVF) of the inguinal WAT of 4- to 6-week-old male C57BL/6 J mice (purchased from Model Animal Research Center of Nanjing University, China). All animal studies were approved by the Ethics Committees at the Nan Jing Medical University. The detached tissues were cut into small pieces in Dulbecco's modified Eagle's medium (DMEM; Gibco, Carlsbad, CA) containing 5\% FBS (Gibco) and $0.2 \%$ collagenase I (Sigma-Aldrich, St. Louis, MO). After 60 mins of digestion at $37^{\circ} \mathrm{C}$, the digestion buffer was filtered through a $100 \mu \mathrm{m}$ nylon mesh (Thermo Fisher Scientific, Waltham, MA, USA) and centrifuged at 1800 rpm for 10 mins. The pellet was then resuspended in DMEM growth medium (GM), supplemented with $10 \%$ FBS (Gibco) and 1\% P/S (Gibco), and seeded onto a 6well plate.

After two more days of $100 \%$ cell confluence, the culture medium was replaced by preadipocyte differentiation medium (PADM; ScienCell), containing 5\% FBS (ScienCell), 1\% preadipocyte differentiation supplement (PAdDS; ScienCell) and 1\% P/S (ScienCell). Seven days after differentiation, the medium was changed to GM as previously described. The cells were then maintained in GM for 7 days when the lipid droplets could be sufficiently displayed. During the whole process of culture and differentiation, the medium was changed every 2 days.

\section{Oil red $\mathrm{O}$ staining}

Mature adipocytes were washed twice with phosphatebuffered saline (PBS; ScienCell) and then fixed in $4 \%$ paraformaldehyde for 30 mins. After washing with PBS, the cells were incubated with $0.2 \%$ Oil Red O (Sigma) solution for 30 mins at $37^{\circ} \mathrm{C}$. Then, the stained cells were washed with PBS and visualized under a microscope (CarlZeiss, Werk Gottingen, Germany).

\section{Triglyceride measurement}

After washing twice with PBS, the intracellular triglycerides of mature adipocytes were determined by using a tissue triglyceride assay kit (Applygen Technologies Inc., 
Beijing, China). According to the manufacturer's instructions, the mature adipocytes were harvested in lysis buffer, and the cell lysates were homogenized by centrifugation and reacted with reagents. The absorbance values were measured at a wavelength of $550 \mathrm{nM}$. Subsequently, the protein content was determined by using the BCA Protein Assay Kit (Thermo Fisher Scientific, Waltham, MA). Finally, the triglyceride content was normalized to the total protein content.

\section{Cell proliferation assay}

For the cell proliferation assay, a WST-8 Cell Counting Kit-8 was used (CCK-8; Dojindo Molecular Technologies, Japan) as reported previously [22]. Human white preadipocytes (1000 cells/well) were seeded onto a 96well plate in PAM containing 5\% FBS, 1\% PAGS and 1\% $\mathrm{P} / \mathrm{S}$ and stimulated with RIFV $(0 \mu \mathrm{M}, 10 \mu \mathrm{M}, 50 \mu \mathrm{M}$, and $100 \mu \mathrm{M}$ ) every day. The cells were analyzed at $0 \mathrm{~h}, 24 \mathrm{~h}$, $48 \mathrm{~h}$ and $72 \mathrm{~h}$. Then, the old medium was replaced with fresh PAM supplemented with 10\% CCK-8 reagent. After incubation at $37^{\circ} \mathrm{C}$ for $60 \mathrm{~min}$, the absorbance was measured by using a Multiskan MK3 microplate reader (Thermo Fisher Scientific) at $450 \mathrm{~nm}$. Finally, the proliferation curve was calculated by using these values.

\section{Cell apoptosis assay}

The human white preadipocytes were cultured on a 6well plate with PAM. After the cells were cultured to $80 \%$ confluence, they were stimulated with RIFV $(0 \mu \mathrm{M}$, $10 \mu \mathrm{M}, 50 \mu \mathrm{M}$, and $100 \mu \mathrm{M})$ every day. After 2 days, the cells were collected, washed twice with PBS and stained with the Annexin V-FITC/PI Apoptosis Detection Kit (Beyotime Institute of Biotechnology, China) according to the manufacturer's instructions. The cell apoptosis distribution was analyzed using flow cytometry. The fraction of the cell population in different quadrants was analyzed by using quadrant statistics. Cells in the lower left quadrant represent survival, the lower right quadrant represents apoptosis and the upper right quadrant represents necrosis or post-apoptotic necrosis.

\section{Cell cycle assay}

The human white preadipocytes were seeded and cultured on a 6-well plate. After the cell density reached $80 \%$, the preadipocytes were treated with different concentrations of RIFV $(0 \mu \mathrm{M}, 10 \mu \mathrm{M}, 50 \mu \mathrm{M}$, and $100 \mu \mathrm{M})$. After incubation for $48 \mathrm{~h}$, the cells were serum-deprived for $12 \mathrm{~h}$ for cell cycle synchronization and then incubated in PAM containing 5\% FBS for another $36 \mathrm{~h}$.

Then, the cells were collected by using trypsin/EDTA (Sigma) and centrifuged at $1500 \mathrm{rpm}$. The cell pellets were washed twice with PBS and fixed in 75\% precooling ethanol (Sigma). After staining with the Cell Cycle and Apoptosis Analysis Kit (Beyotime) according to the manufacturer's instructions, the cell cycle distribution was analyzed by using flow cytometry.

\section{Protein extraction and western blot analysis}

Mature adipocytes were harvested in cold RIPA lysis buffer (Beyotime, China) containing 1\% phenylmethylsulfonyl fluoride (PMSF, Beyotime).The concentrations of protein were determined by using a BCA protein assay kit (Thermo Fisher Scientific). Equal amounts of protein were loaded and analyzed by $10 \%$ SDS-PAGE and transferred to 0.2- $\mu \mathrm{m}$ PVDF membranes. After blocking with $5 \%$ nonfat dry milk, the membranes were probed with the following primary antibodies overnight at $4{ }^{\circ} \mathrm{C}$ : rabbit polyclonal $\beta$ actin (Biosharp, China, BL005B, diluted 1:1000), monoclonal rabbit PPAR- $\gamma$ (Abcam, ab178860, diluted 1:1000), polyclonal rabbit C/EBP- $\beta$ (Abcam, ab32358, diluted 1: 1000), and C/EBP- $\alpha$ (Abcam, ab40761, diluted 1:1000). The membranes were washed 3 times with TBST and incubated with peroxidase-conjugated goat anti-rabbit IgG (Biosharp, China, BL003A, diluted 1:5000) for $1 \mathrm{~h}$ at room temperature. All bands were visualized by using Beyo ECL Plus (Beyotime, China, P0018).

RNA extraction and real-time quantitative PCR (qRT-PCR) Total RNA was isolated from adipocytes by using Trizol reagent (Invitrogen, CA, USA) and extracted by using the RNA prep-pure Cell/Bacteria Kit (TianGen, Beijing, China). cDNA was synthesized from $1 \mu \mathrm{g}$ of total RNA by using the Prime Script $^{\mathrm{tm}}$ RT reagent Kit with g-DNA Eraser (TAKARA BIO, Beijing, China). Real-time PCR was performed with SYBR-Green (Roche, Life Technologies). Measurements were calculated by the $2-^{\Delta \Delta \mathrm{Ct}}$ method and normalized to PPIA. All primers used are listed in Table 1. All real-time PCR reactions were run on a V7 Fast Real-Time PCR system (Applied Biosystems).

\section{DNA plasmid construction and transduction}

The C/EBP- $\beta$ overexpressing vector (pcDNA3.0-C/EBP$\beta$, Genecreate, Wuhan, China) was synthesized by inserting the whole open reading frame of human $C / E B P-\beta$ into pcDNA3.0. According to the manufacturer's instructions of.

Lipofectamine3000 (Invitrogen), $2.5 \mu \mathrm{g}$ C/EBP- $\beta$ plasmids or negative control plasmids were separately mixed with 5 ul Lipo3000 transfection reagent and then added to hWA cells cultured in 6-well plates.To maximize the overexpression efficiency, hWA cells were transfected with plasmids for 2 days before differentiation and repeated at Day 4 of differentiation. Then, the cells were collected at Day 4 and Day 8 of differentiation, and various experiments were carried out subsequently. 
Table 1 Primers sequence used in the paper

\begin{tabular}{lll}
\hline & Direction & Sequence(5'-3') \\
\hline hC/EBP-a & Forward & TGGACAAGAACAGCAACGAG \\
hC/EBP- $\beta$ & Reverse & TTGTCACTGGTCAGCTCCAG \\
& Forward & GACAAGCACAGCGACGAGTA \\
hPPAR- $y$ & Reverse & AGCTGCTCCACCTTCTTCTG \\
& Forward & GCTGTGCAGGAGATCACAGA \\
mC/EBP-a & Reverse & GGGCTCCATAAAGTCACCAA \\
& Forward & TGCGCAAGAGCCGAGATAAA \\
mC/EBP- $\beta$ & Reverse & CCTTCTGTTGCGTCTCCACG \\
mPPAR- $y$ & Forward & AGCGGCTGCAGAAGAAGGT \\
& Reverse & GGCAGCTGCTTGAACAAGTTC \\
mATGL & Forward & GTGCCAGTTCGATCCGTAGA \\
& Reverse & GGCCAGCATCGTGTAGATGA \\
mFABP4 & Forward & TTCACCATCCGCTTGTTGAG \\
& Reverse & AGATGGTCACCCAATTCCTC \\
& Forward & AAGGTGAAGAGCATCATAACCCT \\
\hline
\end{tabular}

\section{C/EBP- $\beta$ promoter luciferase reporter assay}

The full-length of human C/EBP- $\beta$ promoter was synthesized by PCR and inserted downstream of the luciferase gene in the pGL3-Basic firefly luciferase reporter. In the luciferase assays, the C/EBP- $\beta$ promoter luciferase plasmid was transiently transfected into hWA cells cultured in 24-well plates using Lipofectamine2000 (Invitrogen) according to the manufacturer's instructions. Subsequently, the hWA cells were treated with $50 \mu \mathrm{M}$ RIFV. After $72-96 \mathrm{~h}$, cell lysates were analyzed for luciferase activity using the Dual-luciferase Reporter Assay System (Promega Corporation).

\section{Statistical analysis}

The data were analyzed by using SPSS 17.0. All values are presented as the means \pm SEM of at least three independent experiments. Significance of differences between two groups was analyzed by Student's t test. For comparing more than two means, one-way analysis of variance (ANOVA) was employed. $P<0.05$ was considered to be statistically significant.

\section{Results}

RIFV can enter human white preadipocytes and inhibit cell differentiation

First, we utilized FITC to label peptide RIFV and found that FITC-conjugated RIFV could successfully enter human preadipocytes, as shown in Fig. 1a. To examine the role of RIFV on the differentiation of hWA, we added several different concentrations of RIFV $(0 \mu \mathrm{M}, 10 \mu \mathrm{M}, 50 \mu \mathrm{M}$ and $100 \mu \mathrm{M})$ to hWA during their differentiation. Then, Oil Red $\mathrm{O}$ staining and TG measurement were used to determine the effect of RIFV on intracellular lipid accumulation in mature adipocytes at day 8 of differentiation. As shown in Fig. 1b and c, RIFV treatment could lead to significantly reduced lipid accumulation, and the inhibitory effect of RIFV gradually increased with increasing RIFV concentration.

Several transcription regulators, such as CCAAT/ enhancer-binding protein beta $(C / E B P-\beta), C C A A T / e n-$ hancer-binding protein alpha $(\mathrm{C} / \mathrm{EBP}-\alpha)$ and peroxisome proliferator-activated receptor gamma (PPAR- $\gamma$ ), were reported to mediate adipogenesis. To investigate the mechanism by which RIFV inhibited human white preadipocyte differentiation, we measured the mRNA expression of these markers at day 4 by qRT-PCR. The results showed that the expression of $C / E B P-\beta$ and C/EBP- $\alpha$, but not PPAR- $\gamma$, at the mRNA level was downregulated in response to RIFV treatment (Fig. 1d). In addition, western blotting was carried out, and the same result was observed in Fig. 1e. Thus, our data demonstrated that RIFV could inhibit human adipocyte differentiation.

\section{RIFV does not influence the proliferation, apoptosis or cell cycle of hWA}

A CCK-8 assay was used to assess whether RIFV had the ability to affect the proliferation of hWA. Cell viability was detected at $24 \mathrm{~h}, 48 \mathrm{~h}$, and $72 \mathrm{~h}$ after treatment with RIFV $(0 \mu \mathrm{M}, 10 \mu \mathrm{M}, 50 \mu \mathrm{M}$ and $100 \mu \mathrm{M})$. The results showed that RIFV stimulation did not influence the proliferation of hWA (Fig. 2a). Additionally, we observed that the apoptosis and cell cycle of hWA after RIFV treatment were also comparable to that of the negative control (Fig. 2b and c).

\section{RIFV also inhibits the differentiation of mouse primary white preadipocytes}

As we revealed that RIFV could inhibit hWA differentiation, we then investigated whether RIFV had the same inhibitory effect on mouse primary white preadipocyte differentiation. The mWA cells were separately incubated with $10 \mu \mathrm{M}, 50 \mu \mathrm{M}$ and $100 \mu \mathrm{MRIFV}$ during differentiation. Compared to the negative control, the intervention of RIFV resulted in the suppression of adipocyte differentiation, as determined by oil red $\mathrm{O}$ staining on day 8 of differentiation (Fig. 3a). This result is consistent with the decrease observed in TG production (Fig. 3b).In addition, we detected the mRNA expression levels of adipogenic transcription factors and adipocyte-specific genes, including C/EBP$\beta, \mathrm{C} / \mathrm{EBP}-\alpha$, PPAR- $\gamma$, ATGL (adipose triglyceride lipase) and FABP4 (fatty acid binding protein 4), on the indicated days after the induction of differentiation. 


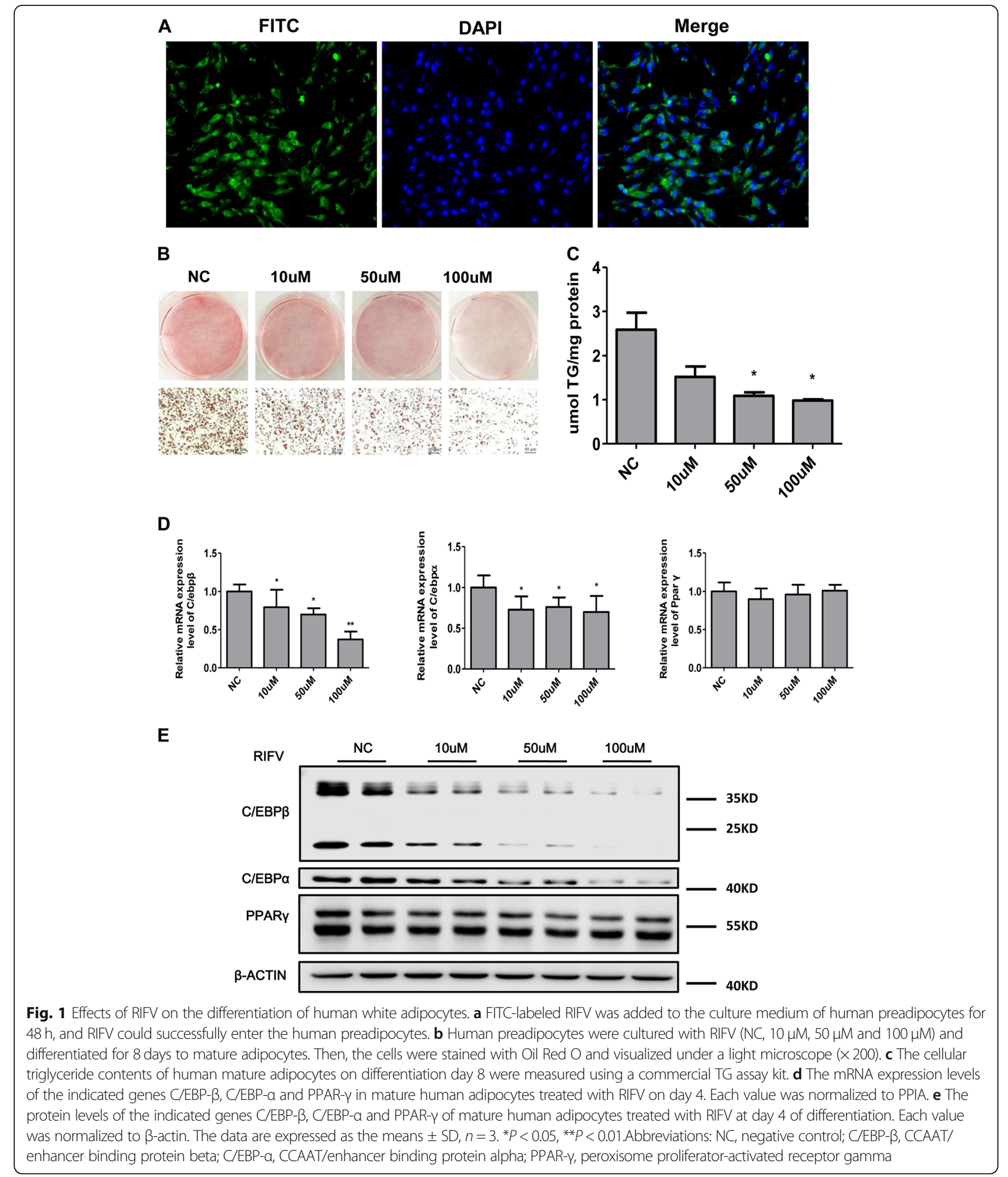

RIFV significantly reduced the expression of the transcription factors $C / E B P-\beta, C / E B P-\alpha$ and PPAR $\gamma$ on day 4 (Fig. 3c). Moreover, the expression levels of ATGL and FABP4 were also downregulated on day 8 .
The hWA differentiation was inhibited by RIFV only at the early stage

The above results showed that C/EBP- $\beta$ was significantly decreased at both the mRNA and protein levels in hWA 

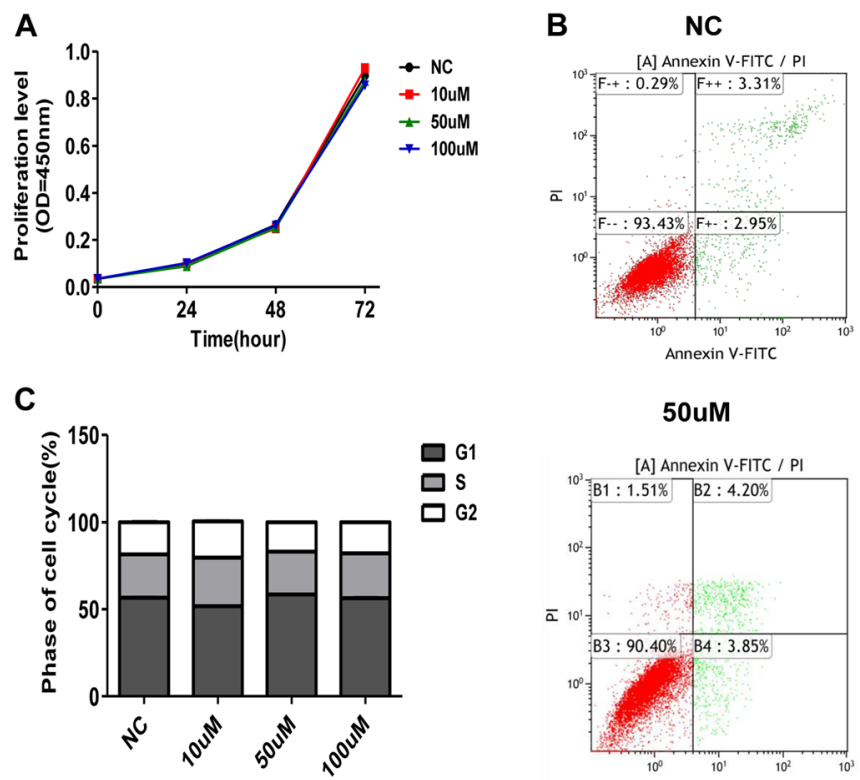

50uM

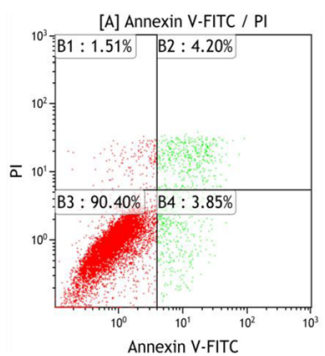

OuM

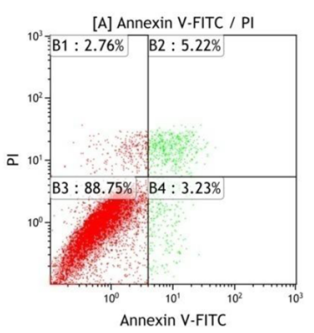

100uM

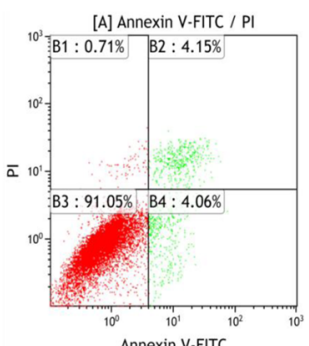

Fig. 2 Peptide RIFV did not influence the proliferation, apoptosis or cell cycle of human white preadipocytes. a Cells were cultured in PAM containing RIFV (NC, $10 \mu \mathrm{M}, 50 \mu \mathrm{M}$ and $100 \mu \mathrm{M})$ for $24 \mathrm{~h}, 48 \mathrm{~h}, 72 \mathrm{~h}$, and the cell proliferation level was assessed via a CCK-8 assay. b Apoptosis and $\mathbf{c}$ cell cycle of human white preadipocytes treated with RIFV for $24 \mathrm{~h}$ were analyzed by flow cytometry. The values represent the means $\pm S D, n=3$. ${ }^{*} P<0.05$, ${ }^{* *} P<0.01$

cells after RIFV treatment. Considering that C/EBP- $\beta$ is an early adipocytes differentiation associated transcription factor, we treated human adipocytes with RIFV separately in the early or later stage of adipogenesis. At the early stage, we added RIFV into culture medium from differentiation Day0 to Day3 during adipogenesis. The Oil Red O staining and TG measurement on differentiation Day8 showed that RIFV could suppress the human adipocytes differentiation (Fig. $4 \mathrm{a}$ and b).The same result was observed that the Fabp4 mRNA expression level of RIFV-treated adipocytes on differentiation Day8 was obviously lower than that of control adipocytes (Fig. 4c). However, at the late stage, the human adipocyte was treated by RIFV from differentiation Day6 to Day8 during adipogenesis and at D8 the treated group showed no difference with the negative control (Fig. $4 d-f$ ).

\section{C/EBP- $\beta$ overexpression can rescue the inhibitory effects of RIFV on adipogenesis}

To detect whether C/EBP- $\beta$ played an important role in the inhibitory effect of RIFV on adipogenesis, we transfected C/EBP- $\beta$ overexpressing plasmids into hWA cells with RIFV treatment on the indicated days. The success of C/EBP- $\beta$ overexpression is demonstrated in Fig. $5 \mathrm{a}$, as the C/EBP- $\beta$ expression level was elevated almost 2.0-fold compared with that in the mock cells. Then, we investigated the effect of $\mathrm{C} /$ EBP- $\beta$ overexpression on adipogenesis in RIFV-treated cells by oil red $\mathrm{O}$ staining and TG assay on the indicated days. The results in Fig. $5 \mathrm{~b}$ and $\mathrm{c}$ show that the overexpression of $C / E B P-\beta$ could result in the promotion of differentiation and rescue the inhibitory effect of RIFV on adipocyte differentiation. Furthermore, we found that the overexpression of C/EBP- $\beta$ in RIFV-treated adipocytes significantly elevated the mRNA levels of C/EBP- $\alpha$ and PPAR- $\gamma$ when compared to those in negative control cells (Fig. $5 \mathrm{~d}$ ).

To test if RIFV directly regulates C/EBP- $\beta$ expression on transcription level, we generated a luciferase reporter vector containing the C/EBP- $\beta$ promoter. Addition of RIFV and transfection of the C/EBP- $\beta$ luciferase expression plasmid in hWA cells resulted in a significant decrease in luciferase activity (Fig. 5e), suggesting a direct inhibition of RIFV on the C/EBP- $\beta$ mRNA transcription expression,

\section{Discussion}

We demonstrated that the peptide RIFV is a novel regulator of human adipocyte differentiation. The peptide RIFV was firstly identified from our peptide database, and gain-of-function studies in human and mouse preadipocytes suggested that RIFV could inhibit adipocyte differentiation. In addition, RIFV was investigated to determine its role in the regulation of the adipogenic gene C/EBP- $\beta$. These findings indicated that RIFV acts as a negative regulator of adipogenesis in human and mouse preadipocytes.

Obesity is a state of abnormal fat accumulation, and hyperplasia (proliferation) and hypertrophy (differentiation) 

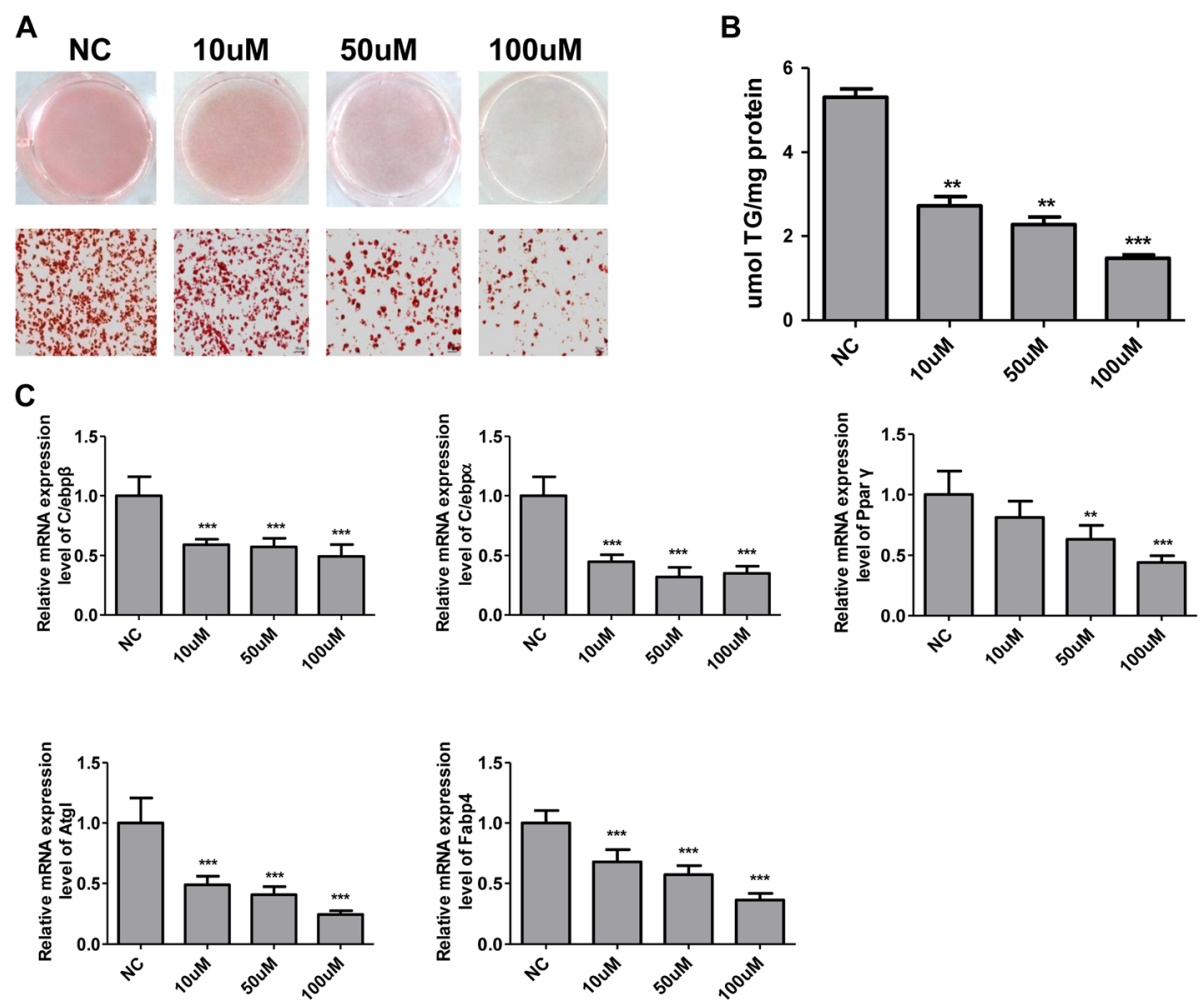

Fig. 3 Effects of RIFV on the differentiation of mouse primary white adipocytes. a The mouse primary white preadipocytes were isolated and cultured with RIFV (NC, $10 \mu \mathrm{M}, 50 \mu \mathrm{M}$ and $100 \mu \mathrm{M})$ and then differentiated into mature adipocytes. The cells were stained with Oil Red O and visualized under a light microscope $(\times 200)$. $\mathbf{b}$ The cellular triglyceride contents of mouse mature adipocytes were measured by a commercial TG assay. $\mathbf{c}$ The mRNA expression levels of the indicated genes C/EBP- $\beta, C / E B P-\alpha$, PPAR- $\gamma$, ATGL and FABP4 in mature mouse adipocytes treated with RIFV at day 4 of differentiation. Each value was normalized to PPIA. The data are expressed as the means \pm SD of three independent experiments. ${ }^{*} \mathrm{P}<0.05,{ }^{*} \mathrm{P}<0.01$.Abbreviations: ATGL, adipose triglyceride lipase; FABP4, fatty acid binding protein 4

are the two main mechanisms. Thus, we investigated the functions of RIFV on obesity from the two aspects. In our study, the differentiation of human white adipocytes was remarkably and dose-dependently inhibited by the peptide RIFV, as supported by Oil Red O staining and intracellular TG measurement. Furthermore, the mRNA and protein levels of adipogenesisassociated key regulators $\mathrm{C} / \mathrm{EBP}-\beta$ and $\mathrm{C} / \mathrm{EBP}-\alpha$ were downregulated in adipocytes after treatment with RIFV. We also found that the proliferation and apoptosis of human white adipocytes was not affected when exposed to the peptide RIFV. In addition, a similar inhibition of RIFV on mouse white adipocyte differentiation was revealed. These findings indicate that the suppression of RIFV on adipocyte differentiation is conserved and that RIFV may combat obesity through its negative effect on hypertrophy.

Previous studies have focused on the molecular mechanism of adipogenesis. The C/EBP family and PPAR- $\gamma$ [23] are important transcriptional factors during adipocyte differentiation. $C / E B P-\beta$ is induced at the early stage of cell differentiation, which plays a significant role in adipogenesis. C/EBP- $\alpha$ and PPAR- $\gamma$ are involved in the late stage, which is essential to differentiate preadipocytes into mature adipocytes. These transcription factors act together at both the gene and protein levels. Many studies have confirmed that inhibiting the expression of $\mathrm{C} / \mathrm{EBP}-\beta$ is closely related to the weakening of adipocyte differentiation [24]. In this study, RIFV was investigated to determine its role in the regulation of the $C / E B P-\beta$ gene. Notably, C/EBP- $\beta$, and C/EBP- $\alpha$ levels were downregulated in human and mouse adipocytes treated with RIFV. Therefore, understanding how the various molecules regulate adiposity may lead to the development of novel therapeutic approaches to human obesity.

In this study, the peptide RIFV was identified from the functional domains of the precursor protein Titin, which plays an important role in the movement generated by skeletal and cardiac muscle contraction [25]. Titin is mainly expressed in striated muscles and reported to be involved in the formation of cardiac muscle fibers and muscle tissue morphogenesis [26]. In addition, the mutation of Titin could result in familial dilated cardiomyopathy [27, 28]. Previously, our group found that RIFV was abundantly expressed in 
A
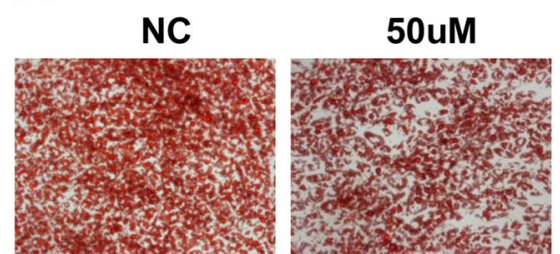

D
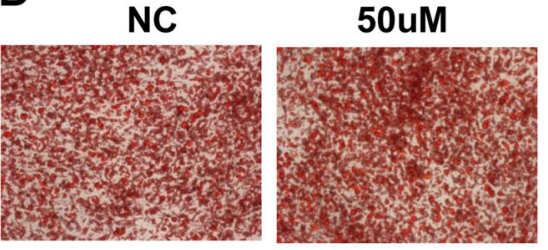

B

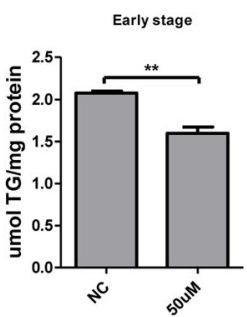

E

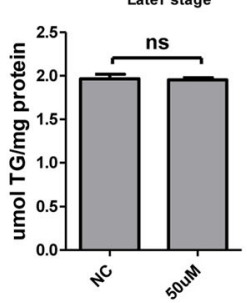

C

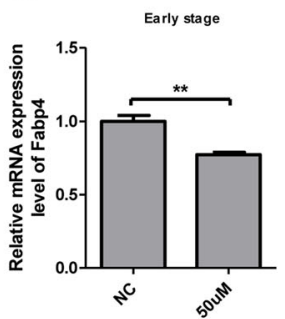

F

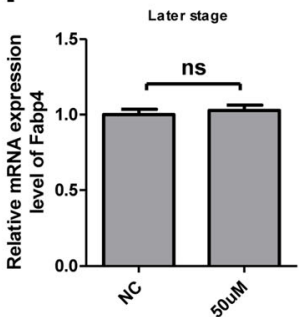

Fig. 4 The human white adipocytes differentiation was inhibited by RIFV at the early stage. a-c The human preadipocytes were cultured with 50 MM RIFV from Day0 to Day3 during adipogenesis. Then the mature adipocytes were stained with Oil Red $\mathrm{O}$ and visualized under a light microscope $(\times 200)$ on differentiation Day8 $\mathbf{a}$. The cellular triglyceride contents of mature adipocytes were measured $\mathbf{b}$. The mRNA expression levels of FABP4 were analyzed by q-RT-PCR $\mathbf{c}$. d-f The human adipocytes were cultured with $50 \mu \mathrm{M}$ RIFV from Day6 to Day8 during adipogenesis. Then the mature adipocytes were stained with Oil Red $O$ and visualized under a light microscope $(\times 200)$ on differentiation Day $8 \mathbf{d}$. The cellular triglyceride contents of mature adipocytes were measured by a commercial TG assay $\mathbf{e}$. The mRNA expression levels of FABP4 were analyzed by q-RT-PCR $\mathbf{f}$. The data are expressed as the means \pm SD of three independent experiments. ${ }^{* *} P<0.01 . n s$. no significance

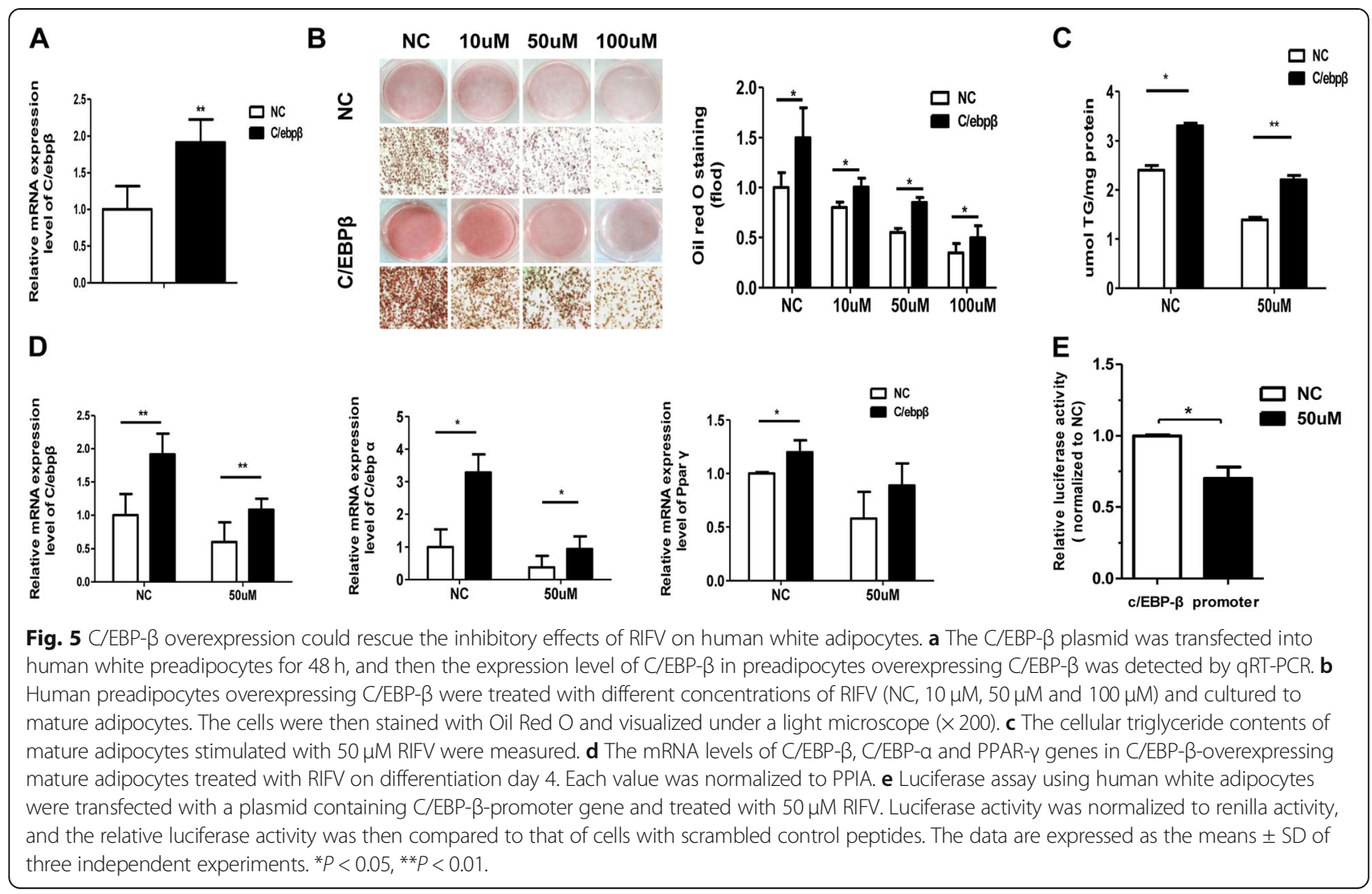


cardiac cells but not in exogenous cultured adipocytes (data not shown).In this study, we screened that this peptide RIFV could participate in the differentiation process of human and mouse preadipocytes. These results suggested that RIFV may act as a potential endocrine molecule in inter organ cross talk to connect the striated muscles with fat tissues, similar to the action of atrial natriuretic peptide ANP as an activator of the lipolysis of adipose tissues [29] and gastric peptide Nesfatin-1 on the regulation of brown adipocyte differentiation [30]. However, this hypothesis remains to be confirmed by further detection.

\section{Conclusions}

In conclusion, our present study revealed that peptide RIFV plays an important role in human adipocyte differentiation by downregulating the transcriptional factors C/EBP- $\beta$. Therefore, RIFV, as a novel peptide, might offer a protective and therapeutic strategy in the management of obesity and obesity-related complications.

\section{Abbreviation}

ATGL: adipose triglyceride lipase; C/EBP-a: CCAAT/enhancer-binding protein alpha; C/EBP- $\beta$ : CCAAT/enhancer-binding protein beta; CCK-8: WST-8 Cell Counting Kit-8;" FABP4: Fatty acid binding protein 4; GLP-1: glucagon-like peptide 1; PPAR-ү: peroxisome proliferator-activated receptor gamma; TG: Triglyceride

\section{Acknowledgements}

Not applicable.

\section{Authors' contributions}

LC and XRG designed the experiments; WZ, DS and YL performed the majority of the experiments and analyzed the data; WZ and LC wrote the paper. LC and XRG obtained the funding and, as such, had full access to all the data in the study and takes responsibility for the integrity of the data and the accuracy of the data analysis. All authors approved the final version of the manuscript.

\section{Funding}

This study was funded by grants from the National Natural Science Foundation of China (Grant No. 81600665, 81770837, 81770866, 81700744, 81670773, and 81600687), the Jiangsu Provincial Medical Innovation Team (CXTDA2017001), Jiangsu Provincial Medical Youth Talent (Grant No. QNRC2016109 and QNRC2016108) and the Jiangsu Provincial Key Research and Development Program (Grant No. BE2016619, BE2018616 and BE2018614).

\section{Availability of data and materials}

All data generated or analyzed during this study are included in this published article.

\section{Ethics approval}

All animal experiments were approved by the Ethics Committees at the Nan Jing Medical University.

\section{Consent for publication}

Not applicable.

\section{Competing interests}

The authors declare that they have no competing interests.

\section{Author details}

'Department of Pediatrics, Nanjing Maternity and Child Health Care Hospital, Women's Hospital of Nanjing Medical University, Nanjing 210029, China.
${ }^{2}$ Department of Internal Medicine, Nantong Maternal and Child Health Care Hospital, Affiliated to Nantong University, Nantong, China. ${ }^{3}$ Hongqiao International Institute of Medicine, Tongren Hospital, Shanghai Jiao Tong University School of Medicine, Shanghai, China.

Received: 11 June 2019 Accepted: 12 December 2019

Published online: 23 December 2019

\section{References}

1. Calle EE, Rodriguez C, Walker-Thurmond K, Thun MJ. Overweight, obesity, and mortality from cancer in a prospectively studied cohort of U.S. adults. N Engl J Med. 2003;348:1625-38.

2. Flegal KM, Graubard BI, Williamson DF, Gail MH. Cause-specific excess deaths associated with underweight, overweight, and obesity. JAMA. 2007; 298:2028-37.

3. Kang JG, Park CY. Anti-obesity drugs: a review about their effects and safety Diabetes Metab J. 2012;36:13-25.

4. Lean ME, Carraro R, Finer N, Hartvig H, Lindegaard ML, Rossner S, Van Gaal L, Astrup A, Investigators NN. Tolerability of nausea and vomiting and associations with weight loss in a randomized trial of liraglutide in obese, non-diabetic adults. Int J Obes. 2014;38:689-97.

5. Arner P, Kulyte A. MicroRNA regulatory networks in human adipose tissue and obesity. Nat Rev Endocrinol. 2015;11:276-88.

6. Shi C, Huang F, Gu X, Zhang M, Wen J, Wang X, You L, Cui X, Ji C, Guo X. Adipogenic miRNA and meta-signature miRNAs involved in human adipocyte differentiation and obesity. Oncotarget. 2016;7:40830-45.

7. Cheon SY, Chung KS, Roh SS, Cha YY, An HJ. Bee venom suppresses the differentiation of Preadipocytes and high fat diet-induced obesity by inhibiting Adipogenesis. Toxins (Basel). 2017;10

8. Lee CW, Seo JY, Kim SL, Lee J, Choi JW, Park YI. Corn silk maysin ameliorates obesity in vitro and in vivo via suppression of lipogenesis, differentiation, and function of adipocytes. Biomed Pharmacother. 2017;93:267-75.

9. Ji C, Guo X. The clinical potential of circulating microRNAs in obesity. Nat Rev Endocrinol. 2019;

10. Sethupathy $P$. The promise and challenge of therapeutic MicroRNA silencing in diabetes and metabolic diseases. Curr Diab Rep. 2016;16:52.

11. Recio C, Maione F, labal AJ, Mascolo N, De Feo V. The potential therapeutic application of peptides and Peptidomimetics in cardiovascular disease. Front Pharmacol. 2016:7:526.

12. Li S, Schmalz G, Schmidt J, Krause F, Haak R, Ziebolz D. Antimicrobial peptides as a possible interlink between periodontal diseases and its risk factors: a systematic review. J Periodontal Res. 2018;53:145-55.

13. Drucker DJ, Nauck MA. The incretin system: glucagon-like peptide-1 receptor agonists and dipeptidyl peptidase- 4 inhibitors in type 2 diabetes. Lancet. 2006;368:1696-705.

14. CdCZ S. Wu J, C BC: egg and soy-derived peptides and Hydrolysates: a review of their physiological actions against diabetes and obesity. Nutrients. 2018:10

15. Flint A, Raben A, Ersboll AK, Holst JJ, Astrup A. The effect of physiological levels of glucagon-like peptide-1 on appetite, gastric emptying, energy and substrate metabolism in obesity. Int J Obes Relat Metab Disord. 2001;25:781-92.

16. Sanchez-Garrido MA, Brandt SJ, Clemmensen C, Muller TD, DiMarchi RD, Tschop MH. GLP-1/glucagon receptor co-agonism for treatment of obesity. Diabetologia. 2017;60:1851-61.

17. Troke RC, Tan TM, Bloom SR. The future role of gut hormones in the treatment of obesity. Ther Adv Chronic Dis. 2014;5:4-14.

18. Elashoff M, Matveyenko AV, Gier B, Elashoff R, Butler PC. Pancreatitis, pancreatic, and thyroid cancer with glucagon-like peptide-1-based therapies. Gastroenterology. 2011;141:150-6.

19. Beeton C, Pennington MW, Norton RS. Analogs of the sea anemone potassium channel blocker ShK for the treatment of autoimmune diseases. Inflamm Allergy Drug Targets. 2011;10:313-21.

20. Upadhyay SK, Eckel-Mahan KL, Mirbolooki MR, Tjong I, Griffey SM, Schmunk G, Koehne A, Halbout B, ladonato S, Pedersen B, et al. Selective Kv1.3 channel blocker as therapeutic for obesity and insulin resistance. Proc Natl Acad Sci U S A. 2013;110:E2239-48.

21. Sodhi K, Maxwell K, Yan Y, Liu J, Chaudhry MA, Getty M, Xie Z, Abraham NG, Shapiro Jl. pNaKtide inhibits $\mathrm{Na/K}$-ATPase reactive oxygen species amplification and attenuates adipogenesis. Sci Adv. 2015;1:e1500781. 
22. Chen $L$, Dai $Y M$, Ji CB, Yang L, Shi CM, Xu GF, Pang LX, Huang FY, Zhang CM, Guo XR. MiR-146b is a regulator of human visceral preadipocyte proliferation and differentiation and its expression is altered in human obesity. Mol Cell Endocrinol. 2014;393:65-74.

23. Farmer SR. Transcriptional control of adipocyte formation. Cell Metab. 2006:4:263-73.

24. Kim YM, Kim IH, Choi JW, Lee MK, Nam TJ. The anti-obesity effects of a tuna peptide on 3 T3-L1 adipocytes are mediated by the inhibition of the expression of lipogenic and adipogenic genes and by the activation of the Wht/beta-catenin signaling pathway. Int J Mol Med. 2015;36:327-34.

25. Walker JS, de Tombe PP. Titin and the developing heart. Circ Res. 2004; 94:860-2.

26. Gregorio CC, Trombitas K, Centner T, Kolmerer B, Stier G, Kunke K, Suzuki K Obermayr $F$, Herrmann B, Granzier $\mathrm{H}$, et al. The NH2 terminus of titin spans the Z-disc: its interaction with a novel 19-kD ligand (T-cap) is required for sarcomeric integrity. J Cell Biol. 1998;143:1013-27.

27. Peng J, Raddatz K, Molkentin JD, Wu Y, Labeit S, Granzier H, Gotthardt M. Cardiac hypertrophy and reduced contractility in hearts deficient in the titin kinase region. Circulation. 2007;115:743-51.

28. Itoh-Satoh M, Hayashi T, Nishi H, Koga Y, Arimura T, Koyanagi T, Takahashi M, Hohda S, Ueda K, Nouchi T, et al. Titin mutations as the molecular basis for dilated cardiomyopathy. Biochem Biophys Res Commun. 2002;291:385-93.

29. Verboven K, Hansen D, Jocken JWE, Blaak EE. Natriuretic peptides in the control of lipid metabolism and insulin sensitivity. Obes Rev. 2017;18: 1243-59.

30. Wang Y, Li Z, Zhang X, Xiang X, Li Y, Mulholland MW, Zhang W. Nesfatin-1 promotes brown adipocyte phenotype. Sci Rep. 2016;6:34747.

\section{Publisher's Note}

Springer Nature remains neutral with regard to jurisdictional claims in published maps and institutional affiliations.

Ready to submit your research? Choose BMC and benefit from:

- fast, convenient online submission

- thorough peer review by experienced researchers in your field

- rapid publication on acceptance

- support for research data, including large and complex data types

- gold Open Access which fosters wider collaboration and increased citations

- maximum visibility for your research: over $100 \mathrm{M}$ website views per year

At $\mathrm{BMC}$, research is always in progress.

Learn more biomedcentral.com/submissions 